\title{
Malaria Preventive Practices among Semi-Urban Dwellers as a Score Card towards Achieving Mdg 6
}

\author{
*Agbo Ha (MBBS, FWACP) ${ }^{1}$, Envuladu Ea (MBBS, FWACP) ${ }^{1}$, Enokela E \\ $(\text { FWACP })^{2}$, Zoakah Ia ((MBBS, FWACP, PGDM, PGD, MBA, HIV/AIDS $)^{1}$ \\ ${ }^{I}$ Department of Community Medicine, University of Jos, Nigeria. \\ ${ }^{2}$ Department of Family Medicine, Usman Danfodio University, Sokoto. Nigeria.
}

\begin{abstract}
:
Background: Malaria control has attracted local and international attention, an on-going effort to curtail its associated health menace. In this on-going quest to curtail its spread, different forms of preventive measures are being instituted such as health education, environmental sanitation, Intermittent Presumptive Treatment (IPT), conventional use of effective antimalarias, distribution and consistent use of Insecticide Treated Nets (ITNs) etc; which collectively ought to positively affect the achievement of the Millennium Development Goal (MDG) 6.

Objectives: The study determined the knowledge and practice of malaria prevention among semi-urban dwellers as a measure of progress in malaria control.

Methodology: This was a community based cross sectional study conducted among adult females selected in each household through a multistage sampling technique. Data was obtained using an interviewer administered semi-structured questionnaires and analysed using statistical software SPSS version 17.0.

Results: Forty eight percent (48.2\%) had good knowledge of malaria while (28.4\%) had good practices of malaria prevention such as sleeping under ITNs (12.3\%); wearing of protective clothing (1.6\%); clearing of surrounding bushes (2.1\%); use of insecticidal sprays (7.1\%); use of mosquito repellent coils (2.2\%) and combination of more than one method of prevention (3.1\%).

Conclusion: Malaria preventive practices should be emphasized in order to facilitate the realization of MDG 6 . Keywords: Malaria, prevention, MDGs
\end{abstract}

\section{Introduction}

Malaria is a mosquito-borne infectious disease of humans which is commonly transmitted via a bite from an infected female Anopheles mosquito. The disease is widespread in the tropics, including most of SubSaharan Africa, Asia, and the Americas. ${ }^{1}$ Currently, about 2 million deaths per year worldwide are due to malaria with majority occurring in children under 5 years of age in the Sub-Saharan African countries. ${ }^{2}$ The CDC estimates that there are 300-500 million cases of malaria each year and more than 1 million people die from it. ${ }^{3}$ The disease is thus a major health problem in most of the tropical and subtropical countries.

The presence of malaria in an area requires a combination of high human population density, high mosquito population density and high rates of transmission from humans to mosquitoes and from mosquitoes to humans. If however any of these factors is lowered sufficiently by medications, mosquito elimination and the prevention of bites, the parasite will eventually disappear from that area, as happened in North America, Europe and much of the Middle East. ${ }^{1,4,5}$ Most semi-urban settings are characterized by such high human population and also high mosquito population which is mostly attributed to farming as their major occupation that provides the favourable vegetations for breeding of the mosquito vectors.

Malaria is preventable and treatable, and history shows that it can be eliminated. Less than a century ago, it was prevalent across the world, including Europe and North America. In high-income countries, aggressive preventive measures and more effective monitoring and treatment gradually brought the disease under control which led to its elimination, which according to the World Health Organization (WHO) refers to the complete interruption of mosquito transmission of the disease for three or more years. In the United States, this milestone was achieved in $1951 .^{6}$

At the Alma Ata declaration of 1978, Primary Health Care was declared the ideal means of providing health care to the populace through scientifically sound and socially acceptable methods and technology. ${ }^{7}$ It also should take into consideration social and cultural factors of the target audience in order to ensure its sustainability. The two primary health care approaches to control malaria are the preventive and curative approaches. ${ }^{8}$ Preventive measures are the use of chemoprophylaxis and vector control activities (through chemical control, environmental control, personal protection and biological control). In all of these, much needs to be emphasized on health educating the individual and community to correct any existing gaps between knowledge and practice of preventive measures. It may be paramount to say here that, such perceived gaps 
between knowledge and practice may have accounted for the low use of preventive measures like the Insecticide Treated Bed nets (ITNs) and Long Lasting Insecticides Treated Nets (LLITNs) despites its availability.

The aim of the WHO global malaria control strategy is to halve the number of annual deaths from malaria by 2010. ${ }^{9}$ The heads of states of African countries, met in April 2000, and committed themselves to malaria control. They committed themselves to an intensive effort to reach the malaria objectives. From surveys of countries in Africa on the current situation of vector control, basically, there are many efforts focused on preventing man-vector contact by large-scale reliance on the implementation of bed nets. ${ }^{10}$ In addition, a historical commitment through spelt out targets and goals was made in the conceptual Millennium Development Goals (MDGs) declared in 2000 to eradicate poverty and improve other socio-economic indicators. Compacting malaria is one of its $6^{\text {th }}$ goals and one of the proposed targets is the proportion of population in malaria risk areas using effective malaria prevention and treatment measures.

Major gains through a combination of interventions have been made in controlling malaria in developing nations through timely diagnosis and treatment using; reliable tests and anti-malarial drugs; indoor spraying with safe insecticides; and the use of long-lasting, insecticide-treated bed nets to protect people from mosquito bites at night. However, current tools and treatments are insufficient to achieve elimination in many countries, let alone global eradication.

Fortunately, global commitment to fighting malaria is being solidified through malaria funding by the Global Malaria Action Plan, the WHO, the Roll Back Malaria Partnership, Bill \& Melinda Gates Foundation etc. ${ }^{6,11}$ However, much still needs to be desired if secure lasting gains against one of humanity's greatest health threats is to be achieved.

Despite all these measures, people still have certain misconception about malaria some are clouded with educational background and their cultural beliefs, which may deter the effective control of the disease especially among the rural dwellers whose major occupation is farming. Vast lands are available for farming in rural and semi-urban areas compared to the typical urban settings and most times farming activities are in close proximity to the houses, which may encourage the breeding of malaria parasites; as a result of all these factors, a clue of their knowledge score and malaria preventive practices ought to be established so that appropriate recommendations may be made if existing gaps are established.

The study determined the knowledge of malaria among the adult females and assessed the type of malaria prevention practiced.

\section{Methodology}

A cross sectional descriptive study was conducted in Gwash community located about $1 \mathrm{~km}$ from the permanent site of the Jos University Teaching Hospital, Jos and about $10 \mathrm{~km}$ from the central business area of the state capital, Jos. A multistage sampling technique was used to select the study participants. Lamingo ward was selected through a Simple Random Sampling Technique (SRST) by balloting from the list of the twenty wards in Jos North Local Government Area of Plateau state; Gwash community was then selected from the list of all the communities in Lamingo ward by a SRST. Out of the 196 households from the 43 houses enlisted, all the 87 households with adult females were selected; all the 253 adult females irrespective of their marital status who gave verbal consent were recruited for the study.

Semi-structured interviewer administered questionnaires was used to obtain information on the sociodemographic characteristics, their knowledge of malaria prevention and the type of malaria prevention practiced. Microsoft Office Excel and Statistical software SPSS version 16.0 were used for data entry and analysis respectively. Test of association between knowledge and practice of malaria prevention was established with Chi square test and a p- value of less than 0.05 was statistically significant.

Out of the four stem questions asked on malaria, 3 or 4 correct answers amounts to a good knowledge score; 2 or below correct answers had poor knowledge. 
III. Results

Table 1: Socio-demographic characteristics of respondents

\begin{tabular}{lcl}
\hline Variable & $\begin{array}{c}\text { Frequency } \\
\text { N= } \mathbf{2 5 3}\end{array}$ \\
\hline Age (In years) & $180(71.1 \%)$ \\
$20-30$ & $65(25.7 \%)$ \\
$40-59$ & $8(3.2 \%)$ \\
$60-79$ & $66(26.1 \%)$ \\
Occupation & $77(30.4 \%)$ \\
Farming & $54(21.3 \%)$ \\
Civil servant & $56(22.1 \%)$ \\
Student & & \\
Others & $37(14.6 \%)$ \\
Educational level & $89(35.2 \%)$ \\
No education & $83(32.8 \%)$ \\
Primary & $44(17.4 \%)$ \\
Secondary & \\
Tertiary & $236(93.3 \%)$ \\
Religion & $17(6.7 \%)$ \\
Christianity & \\
Islam & $88(34.8 \%)$ \\
Marital status & $165(65.2 \%)$ \\
Unmarried & \\
Married & \\
Parity & $57(22.5 \%)$ \\
Nulliparous & $196(77.7 \%)$ \\
Multiparous &
\end{tabular}

Table II: Knowledge of malaria among the study participants

\begin{tabular}{|c|c|c|}
\hline Knowledge & Correct $(\%)$ & Incorrect (\%) \\
\hline 1. What is malaria? & $110(43.5 \%)$ & $143(56.5 \%)$ \\
\hline 2. How is it transmitted? & $123(48.6 \%)$ & $130(51.4 \%)$ \\
\hline 3. What are the ways of preventing malaria? & $213(84.2 \%)$ & $40(15.8 \%)$ \\
\hline $\begin{array}{l}\text { 4. Who can be affected by malaria and who are those most affected } \\
\text { by malaria? }\end{array}$ & $122(48.2 \%)$ & $131(51.8 \%)$ \\
\hline
\end{tabular}

Table III: Knowledge score on malaria

\begin{tabular}{l|cc}
\hline Knowledge & Frequency & $(\boldsymbol{\%})$ \\
\hline Good knowledge & 122 & $(48.2 \%)$ \\
Poor knowledge & 131 & $(51.8 \%)$ \\
\hline Total & $\mathbf{2 5 3}$ & $\mathbf{( 1 0 0 . 0 \% )}$ \\
\hline
\end{tabular}

Less than half of the adult females had a good knowledge of malaria

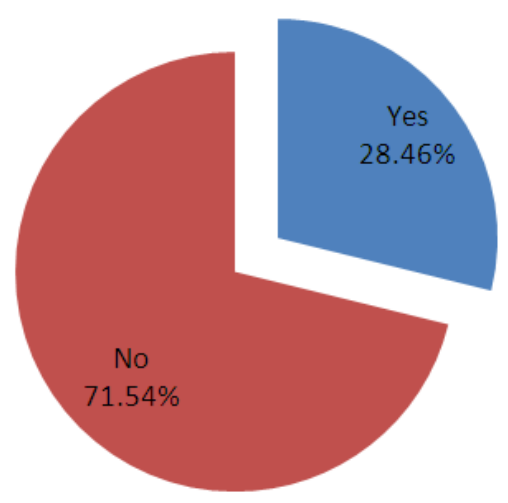

Figure I: Women that practiced at least one form of malaria prevention 
Table IV: Methods of malaria prevention practiced among the respondents

\begin{tabular}{l|l|l}
\hline Methods practised (multiple response was allowed) & Frequency (N=73) & Percent (\%) \\
\hline 1. Use of ITNs only & 31 & 12.3 \\
2. Wearing of protective clothing only & 4 & 5 \\
3. Clearing of surrounding bushes only & 18 & 1.6 \\
4. Frequent use of insecticide sprays only & 5 & 2.0 \\
5. Frequent use of mosquito repellents (coils) only & 8 & 7.1 \\
6. Practice of more than one method of prevention & 181 & 2.4 \\
7. Do not practice any method & 3.1 \\
\hline
\end{tabular}

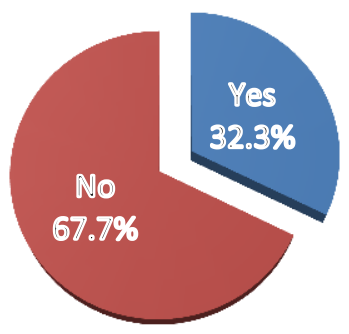

Figure II: Utilization of ITNs two weeks prior to the study Table V: Logistic regression of predictors of preventive practices

\begin{tabular}{llccc}
\hline & $\begin{array}{l}\text { Regression } \\
\text { Coefficient b }\end{array}$ & $\begin{array}{c}\text { Standard error Se } \\
\text { (b) }\end{array}$ & $\mathrm{Z}$ & $\mathrm{P}$ \\
\hline & & & & \\
Constant & 1.997 & 0.824 & & \\
Age & 0.023 & 0.014 & 1.64 & 0.101 \\
Occupation & -0.678 & 0.147 & 4.61 & 0.000 \\
Educational status & -0.173 & 0.165 & 1.05 & 0.294 \\
Knowledge score of & -1.191 & 0.316 & 3.77 & 0.000 \\
malaria & & & & \\
\hline
\end{tabular}

\section{Discussion}

The socio-demographic profile depicts a fairly young population of adult females with a greater percent of them less than 38 years, which is typical of a developing world. Most of the respondents are of the Afezere ethnic group (the indigenous tribe of the community). Majority of the women are literate with primary and secondary school as the highest education obtained.

The general knowledge on malaria was found to be poor especially on their understanding of malaria and on methods of preventing it. The poor level of knowledge established through the responses provided by the respondents on the questions asked on malaria and their low (28.45\%) practice of at least a method of malaria prevention, is not in agreement with this fairly literate community, this discrepancy between literate level and poor practice could have been accounted for by other social and cultural factors such as beliefs and traditions of the people, though these were not established in this study. This low practice of malaria prevention was also reported in the 2008 Nigeria Demographic and Health Survey (NDHS) with the lowest use of ITNs seen in the North Central and South West regions of the country. ${ }^{12}$ All the households surveyed in this study had at least one ITN mostly obtained from the free nationwide distribution Roll Back malaria programme while others purchased theirs from the open market. The 2008 NDHS results indicate that more rural households than urban households own at least one mosquito net. The use of ITNs is currently considered the most cost-effective method of malaria prevention in highly endemic areas. This is the main method of malaria prevention employed in Nigeria.

A logistic regression of the predictors of preventive practices (age, occupation, educational status and knowledge score of malaria) showed a statistically significant relationship $(\mathrm{p}=0.000)$ between age and the knowledge score. An increase in practice of ITNs was also related to increasing level of education in the 2008 NDHS. $^{12}$

The National Malaria Control Strategic Plan (NMCSP) identifies the goals of the Roll Back Malaria (RBM) Strategy and the MDGs goals as the means of achieving national health and development. In addition, it also sets out to increase the ownership and use of ITNs and LLITNs. ${ }^{13-16}$

Among those that practice at least a method of malaria prevention, single use of ITNs, insecticide sprays and repellent coils were most favoured. And among the (3.1\%) that combined methods of prevention, use of ITNs together with insecticide sprays were most practiced. In the elements of the RBM strategy, multiple prevention; through the use of ITNs, environmental management, prophylaxis and insecticide resistance alert 
was advocated. ${ }^{17}$ concurrently are the primary health care preventive approaches which are through the use of chemoprophylaxis and vector control activities (chemical control, environmental control, biological control and personal protection through the use of ITNs, window screens, repellent and wearing of long sleeved shirts and full trousers). ${ }^{18}$

Malaria control has also a particular role to play in the attainment of the health related MDGs, of particular interest is the MDG 6 whose goal is to combat Malaria, HIV/AIDS and other diseases with the specific target to have halted these diseases by the year 2015 (about two years from now).

\section{Conclusion}

The practice of malaria prevention, though commonly through the use of ITNs was low which was also in relation to the community's' poor knowledge of malaria. In all the prevention methods practiced, the single approach was most favoured which on its own may not significantly impact on the attainment of the MDGs 6 at the stipulated time frame.

\section{Recommendation}

Knowledge is a necessary tool that can promote good practice of a health promoting lifestyle. ITNs are being distributed through stand-alone and integration campaigns, more awareness needs to be created to encourage its use especially in combination with other methods.

\section{References}

[1]. Wikipedia. Malaria.2013 [cited 2013 Sept 10]. Available from: http://en.wikipedia.org/wiki/Malaria

[2]. Charles PD. What is malaria? Medicine Net Inc [serial online] 2013 [cited 2013 Sept 10]. Available from: http://www.onhealth.com/script/main/art.asp

[3]. ADAM. Medical Encyclopaedia. Malaria. 2011[cited 2013 Aug 5]. Available from: http://www.ncbi.nlm.nih.gov/pubmedhealth

[4]. Bioku Net. Malaria infection. 2013 [cited 2013 Aug 6]. Available from: http://www.bioku.net/archives/4875

[5]. Tulene national primate research center. Malaria. 2013 [cited 2014 Fed 25]. Available from:

[6]. Bill \& Melinda Gates Foundation. Malaria strategy overview. 2011 [cited 2013 Aug 12]. Available from https://docs.gatesfoundation.org/malaria-strategy.pdf

[7]. World Health Organization/UNICEF. Alma-Ata 1978 primary health care. 1978 [cited 2014 Feb 25]. Available from: http://www.unicef.org/about/history/files/Alma

[8]. Ministry of health Kampala. Malaria control strategic plan 2001/2-2004/5. 2001 [cited 2013 Sept 12]: 9. Available from: http://www.health.go.ug/mcp/umscp.pdf

[9]. Lagos state ministry of health. Malaria control programme. 2014 [cited 2014 Feb 25]. Available from: http://www.lsmoh.com/programme

[10]. Global Governance Initiative. World Economic Forum. 2000 [cited 2013 Sept 12]:17. Available from: http://www.weforum.org/pdf/Initiatives

[11]. Living proof project. Progress against malaria: winning the fight against the deadly disease. 2009 [cited 2013 Sept 13]. Available from: https://docs.gatesfoundation.org/progress-against-malaria.pdf

[12]. Nigerian population commission federal republic of Nigeria. Nigerian Demographic and Health Survey 2008. Preliminary Report. MEASURE DHS, ICF Macro Calverton: Maryland USA; 2009: 189-191

[13]. Thailand bureau of vector-borne disease. National strategic plan for malaria control and elimination in Thailand 2011-2016. 2011 [cited 2014 Feb 25]: 9. Available from:

[14]. http://www.nationalplanningcycles.org/site

[15]. National malaria control programme federal ministry of health Nigeria. A road map for impact on malaria in Nigeria. 2006 [cited 2013 Sept 14]: 8-15. Available from: http://www.rbm.who.int/countryaction/nsp/nigeria.pdf

[16]. Ministry of health Zambia. A Road map for impact on malaria in Zambia 2006-2011. 2006 [cited 2013 Oct 3]. Available from: www.nmcc.org.zm/6NMCPStrategicPlanZMOH

[17]. Ministry of health Zambia. National health strategic plan 2011-2015. [cited 2013 Oct 3]. Available from: http://www.internationalhealthpartnership.net

[18]. Jimoh AAG. Recent trend in the management of malaria in pregnancy. Afr J Cln Exper Microbio. $2006 ; 7$ (2): 120

[19]. Obionu CN. Adequate supply of water and basic sanitation. In: Primary health care for developing countries. $2^{\text {nd }}$ ed. Enugu: Evanseenio; 2007: 87-91 